\title{
Analisis Brand, Inovasi Dan Budaya Terhadap Keputusan Pembelian Songket Tenun Tarutung
}

\section{Brand, Innovation and Culture Analysis of Tarutung Weaving Songket Decisions}

\author{
Nurmaidah Ginting* Demak Claudia Yosephine Simanjuntak** Lasma Ria \\ Tampubolon*** \\ Fakultas Ekonomi, Universitas Prima Indonesia, Medan, Indonesia \\ Coresponding *Email: claudiayoseph8@gmail.com
}

\begin{abstract}
Abstrak
Penelitian ini bertujuan untuk mengetahui pengaruh brand, inovasi, dan budaya terhadap keputusan pembelian Songket Tenun Tarutung di Kabupaten Tapanulin Utara. Sifat penelitian ini adalah penelitian menjelaskan (explanatory) dengan pendekatan kuantitatif. Penelitian ini menggunakan metode Accidental sampling yaitu penduduk wanita yang berada di Kabupaten Tapanuli Utara dan penelitian mengambil data 100 responden dengan sampel menggunakan rumus Slovin. Penelitian ini menggunakan data sekunder dan primer Untuk pengujian validitas dan Uji reliabilitas disebarkan kepada 30 responden penelitian yang merupakan Konsumen Wanita pembelian songket tenun Tarutung di Kabupaten Tarutung. Teknik analisis data yang digunakan adalah regresi linear berganda. Nilai $\mathrm{R}$ adjusted Square $\left(\mathrm{R}^{2}\right)$ adalah 0,553 yang mengindikasikan bahwa variasi variabel brand, inovasi dan budaya mampu menjelaskan variasi variabel keputusan pembelian sebesar 55,3\%. Pengujian secara simultan menujukkan bahwa brand, inovasi dan budaya berpengaruh positif dan signifikan terhadap keputusan pembelian. Pengujian secara parsial bahwa brand, inovasi dan budaya berpengaruh positif dan signifikan terhadap keputusan pembelian.
\end{abstract}

Kata Kunci: brand;inovasi, budaya dan keputusan pembelian

\begin{abstract}
This study aims to determine the effect of brand, innovation, and culture on the purchase decision of Songket Tenun Tarutung in North Tapanulin Regency. The nature of this research is explanatory research with a quantitative approach. This study uses the Accidental sampling method, namely the female population in North Tapanuli Regency and research takes 100 respondents data with a sample using the Slovin formula. This study uses secondary and primary data for testing validity and reliability testing distributed to 30 research respondents who are consumers of women buying Tarutung woven songket in Tarutung Regency. The data analysis technique used is multiple linear regression. The adjusted Square $R$ $\left(R^{2}\right)$ value is 0.553 which indicates that variations in brand, innovation and culture variables are able to explain variations in purchasing decision variables by 55.3\%. Simultaneous testing shows that brand, innovation and culture have a positive and significant effect on purchasing decisions. Partial testing that brand, innovation and culture have a positive and significant effect on purchasing decisions.
\end{abstract}

Keyword: brand; innovation; culture; and purchasing decisions

How to Cite: Ginting, N. Simanjuntak, D.C.Y Ria, L. (2018). Analisis Brand, Inovasi, Dan Budaya Terhadap Keputusan Pembelian Songket Tenun Tarutung. Jurnal Konsep Bisnis dan Manajemen. 5 (1): 76-90 


\section{PENDAHULUAN}

Indonesia memiliki keragaman suku bangsa, adat istiadat, seni budaya, dan bahasa yang khas. Keragaman ini sumber untuk tumbuh dan berkembangnya sebuah kreativitas. Songket merupakan lambang kehalusan seni tenunan diwarisi dari zaman ke zaman dan sebagai upaya membangkitkan warisan budaya Indonesia khususnya warisan dari daerah Sumatera Utara di kabupaten Tapanuli Utara yaitu "Songket Tenun Tarutung".

Saat ini bahwa keberadaan tenun termasuk songket Batak sudah semakin dikenal oleh masyarakat luas, bahkan sudah tidak jarang artis Batak yang menggunakan pakaian pernikahan menggunakan songket Batak yang dihasilkan oleh petenun dari daerah Tarutung. Hal ini menjadi peluang bagi para petenun untuk dapat mempertahankan dan mengembangkan usaha tenun sebagai salah satu aspek bisnis yang akan semakin mengalami kemajuan seiring dengan perkembangan teknologi dan kreativitas para pebisnis.

$$
\text { Menurut Kotler }
$$

menyatakan brand atau merek adalah nama, istilah, tanda, lambang, atau disain, atau kombinasinya, yang dimaksudkan untuk mengidentifikasikan barang atau jasa dari satu penjual atau kelompok penjual dan mendiferensiasikan produk atau jasa dari para pesaing. Kain "Songket Tenun Tarutung memiliki tanda dibuat dengan menggunakan benang pakan dan lungsin. Pada kain songket untuk membentuk corak motif kain biasanya menggunakan teknik anyaman dari benang pakan. Karena sehelai benang pada songket hanya memiliki satu warna saja. Sehingga permukaan selembar kainnya memiliki anyaman benang yang timbul. Ditambah dengan teknik pewarnaan menjadikan corak kain "Songket Tenun Tarutung" begitu indah.

Menurut Suryani (2008) inovasi dalam konsep yang luas sebenarnya tidak hanya terbatas pada produk. Inovasi dapat berupa ide, cara-cara ataupun obyek yang dipersepsikan oleh seseorang sebagai sesuatu yang baru. Inovasi juga sering digunakan untuk merujuk pada perubahan yang dirasakan sebagai hal yang baru oleh masyarakat yang mengalami. Pada umumnya masyakakat di daerah Tarutung sejak kecil sudah diwariskan keterampilan bertenun. Songket Tarutung perlu mengembangkan 
Nurmaida G, Demak Claudia Y.S, Lasma Ria T . Analisis Brand, Inovasi, Dan Budaya Terhadap Keputusan Pembelian Songket Tenun Tarutung

produk untuk dapat bersaing dengan Songket dari daerah lainnya. Inovasi produk menciptakan motif yang berbeda, untuk dapat bersaing di pasar. Selain Inovasi Produk Pendatang baru yang sangat berpengaruh dalam usaha songket tenun adalah pendatang yang bertenun dengan menggunakan tenun mesin. Di mana kedatangan usaha tenun mesin ini mengakibatkan kurangnya minat masyarakat untuk membeli songket hasil tenun tradisional yang diakibatkan oleh keadaan ekonomi. Masyarakat cenderung untuk memilih mengunakan tenun mesin karena Songket hasil tenun mesin lebih murah dibandingkan Songket hasil tenun tradisional.

Menurut Schein (dalam Rivai dan Mulyadi, 2012) menyatakan budaya meliputi asumsi, adaptasi, persepsi dan pelajaran. "Songket Tenun Tarutung" merupakan salah satu warisan budaya Indonesia yang tidak ternilai harganya. "Songket Tenun Tarutung" hadir dalam keseharian gerak masyarakat Indonesia, mulai dari upacara adat yang sakral, hingga busana keseharian yang informal karena adanya perkembangan trend. Motif-motif yang umum dijumpai pada kain "Songket Tenun Tarutung" biasanya mengadopsi dari unsur-unsur budaya setempat.
Berdasarkan latar belakang di atas, maka penelitian ini dimaksudkan untuk mengetahui "Analisis Brand, Inovasi, Dan Budaya Terhadap Keputusan Pembelian Songket Tenun Tarutung Di Kabupaten Tapanuli Utara".

Berdasarkan uraian pada latar belakang diatas Maka permasalahan yang akan diteliti adalah:

Bagaimana Brand berpengaruh terhadap Keputusan Pembelian Songket Tenun Tarutung di Kabupaten Tapanuli Utara?

Bagaimana Inovasi berpengaruh terhadap Keputusan Pembelian Songket Tenun Tarutung di Kabupaten Tapanuli Utara?

Bagaimana Budaya berpengaruh terhadap Keputusan Pembelian Songket Tenun Tarutung di kabupaten Tapanuli Utara?

Bagaimana Brand, Inovasi dan Budaya berpengaruh terhadap Keputusan Pembelian Songket Tenun Tarutung di Kabupaten Tapanuli Utara?

Secara khusus penelitian ini bertujuan untuk:

1. Menguji dan menganalisis bagaimana Brand berpengaruh terhadap Keputusan Pembelian Songket Tenun Tarutung di Kabupaten Tapanuli Utara. 
2. Menguji dan menganalisis bagaiman Inovasi berpengaruh terhadap Keputusan Pembelian Songket Tenun Tarutung di Kabupaten Tapanuli Utara.

3. Menguji dan menganalisis bagaimana Budaya berpengaruh terhadap Keputusan Pembelian Songket Tenun Tarutung di Kabupaten Tapanuli Utara.

4. Menguji dan menganalisis bagaimana Brand, Inovasi dan Budaya berpengaruh terhadap Keputusan Pembelian Songket Tenun Tarutung di Kabupaten Tapanuli Utara.

Penelitian ini diharapkan dapat memberikan manfaat sebagai berikut:

Bagi Penenun, sebagai bahan masukan untuk melakukan inovasi secara terus menerus sesuai keinginan Konsumen untuk mempertahankan Songket Tenun Tarutung menjadi Brand yang diingat Konsumen.

Menambah khasanah penelitian melalui publikasi di jurnal

Ilmiah terakreditas

Brand (merek) adalah adalah aset yang menciptakan nilai bagi pelanggan dengan meningkatkan kepuasan dan menghargai kualitas (Kartajaya, 2010). Menurut Buchory dan Djaslim (2010) merek adalah suatu nama, istilah, tanda, lambang atau dsain atau kombinasi dari semuanya, yang diharapkan mengidentifikasikan barang atau jasa dari sekelompok penjual dan diharapkan akan membedakan barang atau jasa tersebut dari produk-produk pesaing. Brand (merek) merupakan sesuatu yang dibeli oleh kosumen, memiliki nilai dan identitas atau ciri tertentu yang dilindungi secara hukum sehingga tidak dapat ditiru oleh pesaing.

Inovasi adalah transformasi pengetahuan kepada produk, proses dan jasa baru, tindakan menggunakan sesuatu yang baru (Sutarno, 2012). Menurut Dewanto (2014) menyatakan setiap perusahaan menciptakan inovasi untuk memperluas pasar baru serta mempertahankan pangsa pasar mereka saat ini. Menurut Tjiptono (2008) secara sederhana, inovasi bisa diartikan sebagai implementasi praktis sebuah gagasan ke dalam produk atau proses baru.

E.B. Taylor dalam (Ruben dan Stewart, 2017) menyatakan budaya sebagai keseluruhan kompleks yang meliputi pengetahuan, kepercayaan, seni, moral, hukum, adat dan kemampuan lain apa pun, dan kebiasaan yang dipelajari dan diperoleh anggotaanggota dari sebuah masyarakat. Budaya pada saat ini mengalami 
Nurmaida G, Demak Claudia Y.S, Lasma Ria T . Analisis Brand, Inovasi, Dan Budaya Terhadap Keputusan Pembelian Songket Tenun Tarutung

perkembangan yang sangat pesat yang dipengaruhi oleh kemudahan teknologi dan membuat munculnya budaya popular dalam masyarakat.

Keputusan pembelian adalah tahap dimana pembeli telah menentukan pilihannya dan melakukan pembelian produk, serta mengkomsumsinya (Suharno dan Sutarso, 2010). Menurut Feriyanto (2015) pengambilan keputusan adalah melakukan penilaian dan menjatuhkan pilihan, keputusan ini diambil setelah melalui beberapa perhitungan dan pertimbangan alternatif. Pengambilan keputusan konsumen (consumer decision making) adalah proses pengintegrasian yang mengkombinasikan pengetahuan untuk mengevaluasi dua atau lebih perilaku alternatif, dan memilih salah satu di antaranya (Setiadi 2008).

\section{METODE PENELITIAN}

Menurut Sugiyono (2012), pendekatan kuantitatif merupakan penelitian yang digunakan untuk meneliti pada populasi atau sampel tertentu.

Menurut Sugiyono (2011), penelitian deskriptif adalahstatistik yang berfungsi untuk mendeskripsikan atau memberi gambaran terhadap obyek yang diteliti melalui data sampel atau populasi sebagaimana adanya, tanpa melakukan analisis dan membuat kesimpulan yang berlaku umum.

Sifat Penelitian Penelitian ini bersifat asosiatif explanatory disebabkan karena penelitian bertujuan untuk mengetahui hubungan dua variabel atau lebih atau untuk menjelaskan kedudukan variabelvariabel yang diteliti serta hubungan antara suatu variabel dengan variabel yang lain.

Populasi dan Sampel Menurut Sugiyono (2011), populasi adalah wilayah generalisasi yang terdiri atas subjek/objek yang mempunyai kualitas dan karakteristik tertentu yang ditetapkan oleh peneliti untuk dipelajari dan kemudian ditarik kesimpulannya. Populasi dalam penelitian ini adalah jumlah seluruh penduduk wanita di Kabupaten Tapanuli Utara yang berjumlah 14.829 .400 orang.

Sampel Menurut Sugiyono (2011), sampel adalah bagian dari jumlah dan karakteristik yang dimiliki oleh populasi. Uma (2008:78) menyatakan bahwa yang menetukan ukuran sampel dari suatu populasi dapat digunakan rumus Solvin dalam pengambilan sampel. Dengan jumlah populasi (N) sebanyak 14.829 .400 nasabah dan tingkat kesalahan $10 \%$ maka besarnya sampel adalah : 
$\mathrm{n}=14.829 .400$

$$
=99,99
$$

$$
1+14.829 .400(0,1)^{2}
$$

$$
\text { Dibulatkan menjadi }
$$

responden. Menurut Sugiyono (201), teknik pengambilan sampel berdasarkan teknik Accidental sampling yang yaitu penduduk wanita yang berada di Kabupaten Tapanuli Utara bertemu dengan peneliti di lokasi penelitian.

Teknik Pengumpulan Data Adapun teknik pengumpulan data yang digunakan dalam penelitian ini adalah : 1. Daftar pertanyaan (questionnaire), diberikan kepada penduduk wanita yang dijadikan sampel dalam penelitian ini. 2. Studi dokumentasi yaitu mengumpulkan data atau dokumen. 3 . Wawacara, yaitu melakukan tanya jawab kepada pihak yang berhak dan berwenang memberikan data dan informasi sehubungan dengan penelitian ini.

Jenis dan Sumber Data Jenis dan sumber data dalam penelitian ini adalah sebagai berikut : 1. Data primer adalah data yang berasal dari pertanyaan (questionnaire) yang diberikan kepada responden yang dijadikan sampel. 2 . Data sekunder yaitu data yang mendukung data primer yang diperoleh melalui studi dokomentasi.
Dalam penelitian ini model analisis data yang dipakai adalah regresi liner berganda (multiple linier regression) dengan menggunakan rumus seperti berikut:

$$
\mathrm{Y}=\mathrm{a}+\mathrm{b} 1 \mathrm{X} 1+\mathrm{b} 2 \mathrm{X} 2+\mathrm{b} 3 \mathrm{X} 3+\mathrm{e}
$$

Di mana :

$$
\begin{aligned}
& \mathrm{Y} \quad=\text { Variabel Y (Kebijakan Dividen) } \\
& \mathrm{X} 1=\text { Variabel X1 (Brand) } \\
& \mathrm{X} 2=\text { Variabel X2 (Inovasi) } \\
& \text { X3 = Variabel X3 (Budaya) } \\
& \text { b1,b2,b3 = Koefisien regresi variabel } \\
& \mathrm{a}=\text { Konstanta } \\
& \text { e }=\text { Term of error (tingkat }
\end{aligned}
$$

\section{HASIL DAN PEMBAHASAN}

Tabel 1.1 Deskriptif Statistik

Descriptive Statistics
\begin{tabular}{|l|l|l|l|l|l|}
\hline & $\mathrm{N}$ & Mean & Std. Dev & Min & Max \\
\hline $\mathrm{X}_{1}$ & 100 & 20,55 & 3,571 & 8 & 30 \\
$\mathrm{X}_{2}$ & 100 & 20,59 & 3,571 & 8 & 27 \\
$\mathrm{X}_{3}$ & 100 & 20,07 & 3,957 & 6 & 28 \\
$\mathrm{Y}$ & 100 & 41,03 & 8,051 & 20 & 60 \\
\hline
\end{tabular}

Sumber : Hasil Pengolahan Data, 2018

Berdasarkan tabel di atas diperoleh bahwa nilai terendah 8 (8\%) budaya, dan nilai tertinggi sebesar $30(30 \%)$ adalah brand. Rata-rata tertinggi sebesar 41.,03 (41,03\%) yaitu keputusan pembelian.

\section{Uji Normalitas}


Nurmaida G, Demak Claudia Y.S, Lasma Ria T . Analisis Brand, Inovasi, Dan Budaya Terhadap Keputusan Pembelian Songket Tenun Tarutung

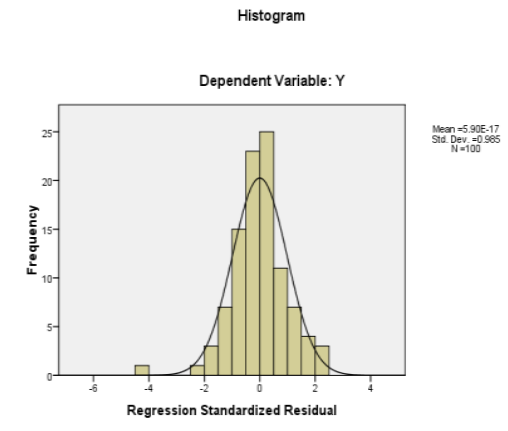

\section{Gambar Grafik Histogram}

Sumber : Hasil Pengolahan Data, 2018
Normal P.P Plot of Regression Standardized Residual

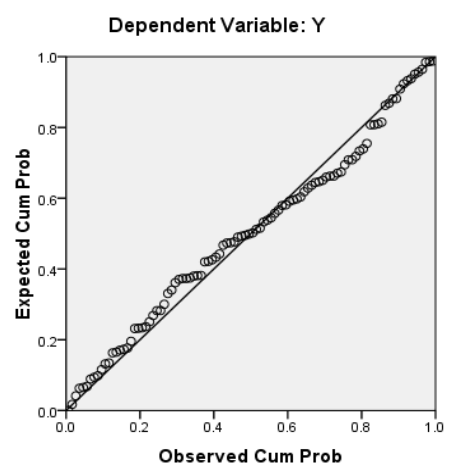

Gambar Grafik PP-Plots

Sumber : Hasil Pengolahan Data, 2018

Tabel 1.2 Hasil Uji Normalitas

Tabel Hasil Uji Normalitas (K-S)

One-Sample Kolmogorov-Smirnov Test

\begin{tabular}{|ll|l|}
\hline & & Unstandardized Residual \\
\hline $\mathrm{N}$ & & 100 \\
Normal Parameters $^{\mathrm{a}}$ & Mean & .0000000 \\
& & 5.30344490 \\
Most Extreme Differences & Std. Deviation & .073 \\
& Absolute & .073 \\
& Positive & -.069 \\
Kolmogorov-Smirnov Z & Negative & .734 \\
Asymp. Sig. (2-tailed) & & .654 \\
\hline
\end{tabular}

Sumber : Hasil Pengolahan Data, 2018

Tabel di atas menunjukkan bahwa seluruh data variabel yang digunakan terdistribusi secara normal. Hal ini dapat dilihat dari nilai Kolmogorov-
Smirnov (K-S) adalah sebesar 0, 734 dengan nilai signifikan lebih besar dari 0,05 yaitu sebesar 0,654 . 
Tabel 1.3 Hasil Uji Multikolinearitas

\section{Uji Multikolinearitas}

Tabel Hasil Uji Multikolinearitas

\begin{tabular}{|l|l|l|}
\hline \multirow{2}{*}{ Model } & \multicolumn{2}{|l|}{ Collinearity Statistics } \\
\cline { 2 - 3 } & Tolerance & VIF \\
\hline (Constant) & & \\
Brand & .477 & 2.096 \\
Inovasi & .469 & 2.131 \\
Budaya & .552 & 1.812 \\
\hline
\end{tabular}

Sumber : Hasil Pengolahan Data, 2018

Brand $\left(\mathrm{X}_{1}\right)$ dengan nilai tolerance $0,477>0,10$ dan nilai VIF sebesar 2,096

$<$ 10. Inovasi $\left(\mathrm{X}_{2}\right)$ dengan nilai tolerance $0,469>0,10$ dan nilai VIF

sebesar 2,131< 10 . Dan budaya $\left(X_{3}\right)$ dengan nilai tolerance $0,552>0,10$ dan nilai VIF sebesar $1,812<10$.

\section{Uji Heterokedastisitas}

Pengujian heteroskedastisitas dapat dilakukan dengan dua cara yaitu melalui analisis grafik dan uji Glejser. Analisis grafik dapat dilihat melalui

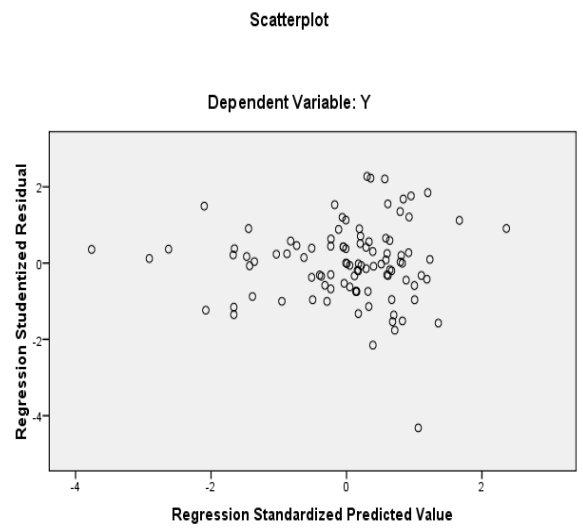

Gambar Sacatterplot

Sumber : Hasil Pengolahan SPSS, 2018

Sedangkan uji statistik melalui uji

Dlejser dapat dilihat sebagai berikut : 
Nurmaida G, Demak Claudia Y.S, Lasma Ria T . Analisis Brand, Inovasi, Dan Budaya Terhadap Keputusan Pembelian Songket Tenun Tarutung

Tabel 1.4 Hasil Uji Glejser

\section{Coefficients ${ }^{a}$}

\begin{tabular}{|c|c|c|c|c|c|c|}
\hline \multirow{2}{*}{\multicolumn{2}{|c|}{ Model }} & \multicolumn{2}{|c|}{$\begin{array}{l}\text { Unstandardized } \\
\text { Coefficients }\end{array}$} & \multirow{2}{*}{$\begin{array}{l}\text { Standardized } \\
\text { Coefficients } \\
\text { Beta }\end{array}$} & \multirow[b]{2}{*}{$\mathrm{t}$} & \multirow[b]{2}{*}{ Sig. } \\
\hline & & B & Std. Error & & & \\
\hline \multirow[t]{4}{*}{1} & (Constant) & -482 & 2,299 & & -209 & ,835 \\
\hline & $\mathrm{X} 1$ & ,095 & 144 & ,094 & 658 & ,512 \\
\hline & x2 & -073 & 145 & -,073 & - 504 & 615, \\
\hline & X3 & 196 & ,121 & ,216 & 1,618 & ,109 \\
\hline
\end{tabular}

a. Dependent Variable: abs_res2

Sumber : Hasil Pengolahan Data, 2018

Tabel IV.9 di atas menunjukkan bahwa variabel-variabel independen yaitu Brand (X1) memiliki nilai signifikan 0,512, Inovasi (X2) memiliki nilai signifikan 615, dan Budaya (X3) memiliki nilai signifikan 0,109, Hal ini enunjukkan bahwa model regresi tidak terdapat heteroskedastisitas karena nilai signifikan variabel independen ada yang dibawah 0,05 .

\section{Pengujian Analisis Regresi Berganda}

Tabel 1.5 Hasil Uji Model Analisis Penelitian

\section{Tabel Hasil Uji Model Analisis Penelitian}

\begin{tabular}{|c|c|c|c|c|c|}
\hline \multirow[b]{2}{*}{ Model } & \multicolumn{2}{|c|}{$\begin{array}{c}\text { Unstandardized } \\
\text { Coefficients } \\
\end{array}$} & \multirow{2}{*}{$\begin{array}{c}\text { Standard } \\
\text { ized } \\
\text { Coefficie } \\
\text { nts } \\
\\
\text { Beta }\end{array}$} & \multirow[b]{2}{*}{$t$} & \multirow[b]{2}{*}{ Sig. } \\
\hline & B & Error & & & \\
\hline $\begin{array}{ll}1 & \text { (Cons } \\
& \tan t)\end{array}$ & 2,793 & 3,499 & & ,798 & ,427 \\
\hline $\mathrm{X} 1$ & 601 & 219 & 267 & 2,741 & ,007 \\
\hline $\mathrm{X} 2$ & ,592 & 221 & 263 & 2,675 & ,009 \\
\hline $\mathrm{X} 3$ & 682 & 184 & ,335 & 3,705 & ,000 \\
\hline
\end{tabular}

a.Dependent Variable: 
Keputusan Pembelian

Sumber : Hasil Pengolahan Data, 2018

Melalui data tabel IV.13 di atas, maka persamaan regresi linier berganda yang terdapat dalam penelitian ini adalah :

Keputusan Pembelian $=2,793+$ 0,601 brand $+0,592$ inovasi + 0,682budaya

\section{Koefisien Determinasi Hipotesis}

Hasil pengujian nilai koefisien determinasi $\left(\mathrm{R}^{2}\right)$ dapat dilihat pada tabel sebagai berikut:

Tabel 1.6 Hasil Pengujian Koefisien Determinasi

Tabel Hasil Pengujian Koefisien Determinasi

Model Summaryb

\begin{tabular}{|c|c|r|r|r|}
\hline & & & Adjusted & $\begin{array}{l}\text { Std. Error } \\
\text { of the } \\
\text { Model }\end{array}$ \\
\hline 1 & $.752^{\mathrm{a}}$ & .566 & .553 & 5.386 \\
\hline
\end{tabular}

Sumber : Hasil Pengolahan Data, 2018

Nilai $R$ Square pada tabel IV.14 adalah 0,566. Nilai Adjusted R Square adalah 0,553 atau sama dengan 55,3\% artinya kemampuan variabel bebas $\operatorname{Brand}\left(\mathrm{X}_{1}\right)$, Inovasi $\left(\mathrm{X}_{2}\right)$, dan Budaya $\left(\mathrm{X}_{3}\right)$ dalam menjelaskan variasi variabel terikat yaitu Keputusan Pembelian (Y) adalah sebesar $55,3 \%$ sedangkan $44,6 \%$ dijelaskan oleh variabel lain yang tidak diteliti dalam penelitian ini.

\section{Pengujian Hipotesis Secara Simultan (Uji F)}

Uji simultan (uji F) dapat dilihat pada tabel berikut ini :

Tabel 1.7 Hasil Uji Simultan (Uji F)

\begin{tabular}{|c|c|c|c|c|c|}
\hline \multicolumn{6}{|c|}{ ANOVA $^{b}$} \\
\hline Model & Sum of Squares & df & Mean Square & $\mathrm{F}$ & Sig. \\
\hline 1 Regression & 3632,384 & 3 & 1210,795 & 41,744 &, $000^{\mathrm{a}}$ \\
\hline Residual & 2784,526 & 96 & 29,005 & & \\
\hline Total & 6416,910 & 99 & & & \\
\hline
\end{tabular}

a.Predictors: (Constant), budaya, brand, Inovasi

Sumber : Hasil Pengolahan Data, 2018

b.Dependent Variable: Keputusan Pembelian 
Nurmaida G, Demak Claudia Y.S, Lasma Ria T . Analisis Brand, Inovasi, Dan Budaya Terhadap Keputusan Pembelian Songket Tenun Tarutung

Berdasarkan hasil uji simultan (uji F) pada tabel diatas, maka diperoleh nilai Fhitung adalah sebesar 41,744 dengan signifikan 0,000. Hasil $F_{\text {tabel }}$ adalah 2,70. Dengan demikian, nilai $F_{\text {hitung }}>F_{\text {tabel }}$ $(41,744>2,70)$ dan signifikan lebih kecil dari $0,05(0,000<0,05)$ yang artinya $\mathrm{H}_{0}$ ditolak dan $\mathrm{H}_{\mathrm{a}}$ diterima. Jadi, dapat disimpulkan bahwa Brand ( $\left.\mathrm{X}_{1}\right)$, Inovasi $\left(\mathrm{X}_{2}\right)$, dan Budaya $\left(\mathrm{X}_{3}\right)$ secara simultan berpengaruh dan signifikan terhadap Keputusan Pembelian Songket Tenun Tarutung.

Tabel 1.8 Hasil Uji Simultan (Uji F)

Pengujian Hipotesis Secara

\section{Parsial (Uji t)}

Uji simultan (uji t) dapat dilihat pada tabel berikut ini :

Tabel Hasil Uji Parsial (Uji t)
Sumber : Hasil Pengolahan Data, 2018

\begin{tabular}{|c|c|c|c|c|c|}
\hline \multirow[b]{3}{*}{ Model } & \multicolumn{3}{|c|}{ Coefficients $^{a}$} & \multirow[b]{3}{*}{$\mathbf{T}$} & \multirow[b]{3}{*}{ Sig. } \\
\hline & \multicolumn{2}{|c|}{$\begin{array}{l}\text { Unstandardize } \\
\text { d Coefficients }\end{array}$} & \multirow{2}{*}{\begin{tabular}{|c}
$\begin{array}{c}\text { Standardi } \\
\text { zed } \\
\text { Coefficient } \\
\text { s }\end{array}$ \\
Beta \\
\end{tabular}} & & \\
\hline & B & $\begin{array}{c}\text { Std. } \\
\text { Error }\end{array}$ & & & \\
\hline \multirow[t]{2}{*}{1 (Constant) } & & & & & \\
\hline & 2.793 & 3.499 & & .798 & .427 \\
\hline Brand & .601 & .219 & .267 & 2.741 & .007 \\
\hline Inovasi & .592 & .221 & .263 & 2.675 & .009 \\
\hline Budaya & & & .335 & 3.705 & .000 \\
\hline
\end{tabular}

Berdasarkan hasil uji parsial (uji t) pada tabel maka dapat dijelaskan sebagai berikut :

Variabel Brand $\left(\mathrm{X}_{1}\right)$ diperoleh $t_{\text {thitung }}>t_{\text {tabel }}$ dengan hasil $2,741>1,985$ dan nilai signifikan sebesar 0,007 0,05 maka $\mathrm{H}_{0}$ ditolak dan $\mathrm{H}_{\mathrm{a}}$ diterima berarti secara parsial brand $\left(\mathrm{X}_{1}\right)$ berpengaruh positif dan signifikan terhadap Keputusan Pembelian (Y) Songket Tenun Tarutung di Kabupaten Tapanulin Utara.

Variabel Inovasi $\left(\mathrm{X}_{2}\right)$ diperoleh hasilnya $t_{\text {hitung }}>t_{\text {tabel }}$ dengan hasil 2,675
$>1,985$ dan nilai signifikan sebesar $0,009<0,05$ maka $\mathrm{H}_{0}$ ditolak dan $\mathrm{H}_{a}$ diterima berarti secara parsial Inovasi $\left(\mathrm{X}_{2}\right)$ berpengaruh positif dan signifikan terhadap Keputusan Pembelian (Y) Songket Tenun Tarutung di Kabupaten Tapanulin Utara.

Variabel Budaya $\left(\mathrm{X}_{3}\right)$ thitung $>$ tabel dengan hasil 3,705>1,985dan nilai signifikan hasilnya sebesar $0,000<0,05$ maka $\mathrm{H}_{0}$ ditolak dan $\mathrm{H}_{\mathrm{a}}$ diterima berarti secara parsial Budaya $\left(\mathrm{X}_{3}\right)$ berpengaruh positif dan signifikan terhadap Keputusan Pembelian (Y) Songket 
Tenun Tarutung di Kabupaten Tapanulin Utara.

HASIL DAN PEMBAHASAN

Hasil Hipotesis Brand ( $\left.\mathrm{X}_{1}\right)$ terhadap Keputusan Pembelian (Y) Songket Tenun Tarutung di Kabupaten Tapanulin Utara.

Variabel Brand $\left(\mathrm{X}_{1}\right)$ diperoleh $t_{\text {hitung }}>$ ttabel $_{\text {dengan }}$ hasil $2,741>1,985$ dan nilai signifikan sebesar 0,007 $<0,05$ maka $\mathrm{H}_{0}$ ditolak dan $\mathrm{H}_{a}$ diterima berarti secara parsial brand $\left(\mathrm{X}_{1}\right)$ berpengaruh positif dan signifikan terhadap Keputusan Pembelian (Y) Songket Tenun Tarutung di Kabupaten Tapanulin Utara.

Sesuai dengan menurut teori Kotler (2008:188-192) konsumen membentuk preferensi antar merek dalam kumpulan pilihan. Konsumen mungkin juga membentuk maksud untuk membeli merek yang paling disukai. Tanpa memperhatikan apa yang dapat dilakukan pemasar, konsumen mempunyai keterlibatan rendah dengan keputusan pembelian, mereka mungkin mengikuti rute peripheral. Pemasar harus memberi perhatian khusus untuk memberikan satu atau lebih pertanda positif kepada konsumen untuk mengesahkan pilihan merek.

Hasil penelitian diatas sesuai dengan penelitian terdahulu menurut
Wicaksono (2015) bahwa Merek dan Desain Berpengaruh Positif Dan Signifikan Terhadap Minat Beli Konsumen.

Daerah Sumatera Utara yang pada umumnya suku batak sudah lama mengenal brand Songket Tenun Tarutung dan lebih tertarik kepada Songket Tenun Tarutung karena saat ini memiliki banyak motif yang berinovasi dan mengikuti trend masa kini. Masyarakat batak didaerah Tarutung sudah mengenal merek Songket Tenun Tarutung dan memiliki banyak jenis Songket tenun Tarutung. Masyarakat Tarutung lebih percaya diri menggunakan Songket tenun Tarutung yang kualitasnya sangat bagus. Dari banyaknya jenis Songket tenun Tarutung memiliki ciri khas sehingga masayakat tarutung lebih mudah mengingat dari jenis Songket tenun Tarutung.

Hasil Hipotesis Inovasi terhadap Keputusan Pembelian (Y) Songket Tenun Tarutung di Kabupaten Tapanulin Utara.

Variabel Inovasi (X2) diperoleh hasilnya thitung> ttabel dengan hasil 2,675 >1,985 dan nilai signifikan sebesar 0,009 < 0,05 maka H0 ditolak dan Ha diterima berarti secara parsial Inovasi (X2) berpengaruh positif dan 
Nurmaida G, Demak Claudia Y.S, Lasma Ria T . Analisis Brand, Inovasi, Dan Budaya Terhadap Keputusan Pembelian Songket Tenun Tarutung

signifikan terhadap Keputusan

Pembelian (Y) Songket Tenun Tarutung di Kabupaten Tapanulin Utara.

Sesuai dengan menurut teori Kotler Menurut Kotler (2008) Pengurangan biaya merupakan produk baru yang menyediakan produk yang daya kerja/kegunaanya serupa dengan harga yang lebih murah atau rendah, hal ini dimaksudkan mempengaruhi keputusan konsumen untuk membeli suatu produk dan hal ini berdampak pada meningkatnya volume penjualan suatu produk.

Hasil penelitian ini sesuai dengan menurut Andiyanto (2016) bahwa Inovasi Celebrity Endorser dan harga Berpengaruh positif Dan Singnifikan terhadap Keputusan Pembelian.

Desain yang dikembangkan untuk mempertahankan hasil karya Batak yang kemudian diekspresikan dalam rancangannya. Memang desain baru terus digali dan dikembangkan dan mempertahankan ciri dan motif yang ada. Dan menambah bahan benang yang digunakan dan pewarna yang dipakai untuk menambah kesan songket lebih menarik. Eksistensi songket Tenun Tarutung sebagai tenunan khas Batak yang asli, akan tetap dipertahankannya. Setiap kelompok partonun yang dibina, tetap dipertahankan ciri dan spesifiknya masing-masing.

$$
\text { Hasil Hipotesis Budaya }
$$
terhadap Keputusan Pembelian (Y ) Songket Tenun Tarutung di Kabupaten Tapanulin Utara.

Variabel Budaya (X3) thitung> ttabel dengan hasil 3,705>1,985dan nilai signifikan hasilnya sebesar $0,000<$ 0,05 maka H0 ditolak dan Ha diterima berarti secara parsial Budaya (X3) berpengaruh positif dan signifikan terhadap Keputusan Pembelian (Y) Songket Tenun Tarutung di Kabupaten Tapanulin Utara.

Menurut Kotler (2008:87) kelas budaya, subbudaya, dan sosial sangat mempengaruhi perilaku pembelian konsumen. Masyarakat membentuk kepercayaan, nilai, dan norma yang menggambarkan sebagian besar dan prefensial konsumen. Masyrakat menyerap, secara hampir tidak sadar, pandangan dunia yang mendefenisikan hubungan mereka bagi diri mereka sendiri, orang lain, organisasi, masyarakat, alam, dan alam semesta.

Hasil penelitian ini sesuai dengan menurut Okkysantria, 2014 bahwa Kebudayaan, Sosial, Pribadi Dan Psikologis Konsumen Berpengaruh Positif Dan Signifikan Terhadap Keputusan Pembelian. 
Penenun Songket Tenun Tarutung memerlukan koordinasi yang baik gunakan. Songket di buat dengan pola tertentu yang di kombinasi dengan benang dan warna yang melambangkan menjadi budaya daerah tarutung. Dalam budaya etnik batak Sumetera Utara Songket di gunakan pada acara adat seperti perkawinan penyambutan tamutamu penting dan acara ibadah Gereja.

\section{SIMPULAN DAN SARAN}

\section{simpulan}

Berdasarkan hasil analisis data dan pembahasan yang telah dikemukakan pada bab sebelumnya, maka dapat diambil kesimpulan sebagai berikut :

Variabel Brand secara parsial berpengaruh positif dan signifikan terhadap Keputusan Pembelian Songket Tenun Tarutung di Kabupaten Tapanulin Utara.

Variabel Inovasi secara parsial berpengaruh positif dan signifikan terhadap Keputusan Pembelian Songket Tenun Tarutung di Kabupaten Tapanulin Utara.

Variabel Budaya berpengaruh positif dan signifikan terhadap Keputusan Pembelian Songket Tenun Tarutung di Kabupaten Tapanulin Utara

Variabel Brand, Inovasi dan Budaya berpengaruh dan signifikan terhadap Keputusan Pembelian Songket Tenun Tarutung di Kabupaten Tapanulin Utara

\section{Saran}

Berdasarkan hasil penelitian yang telah dilakukan oleh peneliti, saransaran yang dapat peneliti berikan adalah sebagai berikut :

Songket Tenun Tarutung harus senantiasa menciptakan persepsi brand produk yang baik kepada konsumen dengan melakukan inovasi produk untuk mempertahankan songket tenun Tarutung dipasar dan memperbanyak promosi baik melalui periklanan, dan promosi disosial media.

Penenun harus melakukan inovasi yang mempunyai pengaruh terhadap keputusan pembelian maka inovasi produk tidak hanya pada desainnya saja, tetapi juga pada bahan dasar, bahan pewarnaan songket tenun dan teknikteknik lain yang dapat membedakan produk songket tenun Tarutung yang lainnya.

Penenun diharapkan dapat meningkatkan kualitas produk untuk mempertahankan songket tenun Tarutung sebagai budaya daerah Batak.

Bagi peneliti selanjutnya, agar menggali faktor-faktor lain misalnya menggunakan variabel lain atau menambah variabel bebas seperti: 
Nurmaida G, Demak Claudia Y.S, Lasma Ria T . Analisis Brand, Inovasi, Dan Budaya Terhadap Keputusan Pembelian Songket Tenun Tarutung

Bauran pemasaran, dan kualitas produk yang lainnya yang mempengaruhi keputusan pembelian untuk diteliti pada masa yang akan datang.

\section{UCAPAN TERIMA KASIH}

Peneliti mengucapkan terima kasih kepada KEMENRISTEK DIKTI yang telah mendanai penelitian ini dan terima kasih kepada seluruh pihak yang telah membantu terlaksananya penelitian ini.

\section{DAFTAR PUSTAKA}

Buchory, A H dan Saladin, D. 2010. Edisi Pertama. Manajemen Pemasaran. Linda Karya. Bandung.

Dewanto W, Hendrati D $M$, Anggraeni P, Grisna A dan Indriany A. 2014. Manajemen Inovasi. Edisi 1. Andi Offset. Yogyakarta.

Dyca Okkysantria, 2014. Analisis Pengaruh Kebudayaan, sosial, pribadi dan psikologis konsumen usia muda terhadap keputusan pembelian makanan CEPAT SAJI MCDONALD'S

Feriyanto, A dan Endang, S T. 2015. Pengantar Manajemen (3in 1). Meditera. Kebumen.

Kartajaya. 2010. Brand Operation. Erlangga. Jakarta.

Kotler, P. \& Keller, (2008). Manajemen Pemasaran., Jilid 1. Erlangga. Jakarta
Kotler, P. (2009). Manajemen Pemasaran, Jilid 1. Edisi 13. Erlangga. Jakarta.

Rivai, V dan Mulyadi, D. (2012). Kepemimpinan dan Perilaku Organisasi. PT RajaGrafindo Persada. Jakarta.

Ruben, Brent D. dan Stewart, Lea P. (2017). Komunikasi dan Perilaku Manusia. Edisi Kelima. RajaGrafindo Persada. Jakarta.

Roni Andiyanto, (2016). Pengaruh Inovasi, Celebrity Endorser Dan Harga Terhadap Keputusan Pembelian Sepatu Futsal Adidas Di Yogyakarta

Satria Adhi Wicaksono,( 2015). Pengaruh Merek Dan Desain Terhadap Minat Beli Konsumen

Sugiyono. (2011). Metode PenelitianPendidika (Pendekatan Kuantitatif, Kualitatif, dan $R \& D$ ). Alfabeta. Bandung

Suharno dan Yudi Sutarso. (2010). Marketing in Practice. Graha Ilmu. Yogyakarta.

Suryani, Tatik. 2008. Perilaku Konsumen; Implikasi Pada Strategi Pemasaran. Graha Ilmu. Yogyakarta

Sutarno. 2012. Serba-Serbi Manajemen Bisnis. Edisi 1. Graha Ilmu.Yogyakarta.

Sekaran U. 2008. Metedologi Penelitian Untuk Bisnis. Salemba Empat. Jakarta 
Jurnal Konsep Bisnis dan Managemen, 5 (1) Nov 2018: 76-90 